Wilfrid Laurier University

Scholars Commons @ Laurier

$9-1983$

\title{
Human Pancreas GH-Releasing Factor Analog Restores High- Amplitude GH Pulses in CNS Lesion-Induced GH Deficiency
}

Gloria Schaffer Tannenbaum

Montreal Children's Hospital

Rudy Eikelboom

Wilfrid Laurier University, reikelboom@wlu.ca

Nicholas Ling

Salk Institute for Biological Studies

Follow this and additional works at: https://scholars.wlu.ca/psyc_faculty

\section{Recommended Citation}

Schaffer Tannenbaum, Gloria; Eikelboom, Rudy; and Ling, Nicholas, "Human Pancreas GH-Releasing Factor Analog Restores High-Amplitude GH Pulses in CNS Lesion-Induced GH Deficiency" (1983). Psychology Faculty Publications. 9.

https://scholars.wlu.ca/psyc_faculty/9

This Article is brought to you for free and open access by the Psychology at Scholars Commons @ Laurier. It has been accepted for inclusion in Psychology Faculty Publications by an authorized administrator of Scholars Commons@ @aurier. For more information, please contact scholarscommons@wlu.ca. 
HUMAN PANCREAS GH-RELEASING FACTOR ANALOG RESTORES HIGH-AMPLITUDE GH PULSES IN CNS LESION-INDUCED GH DEFICIENCY GLORIA SHAFFER TANNENBAUM', ROELOF EIKELBOOM, AND NICHOLAS LING

Departments of Pediatrics, and Neurology and Neurosurgery, McGill University, Montreal, Quebec H3H IP3, Canada, and Laboratories for Neuroendocrinology, Salk Institute for Biological Studies, La Jolla, California 92037, USA

Transmitted by Claude Desjardins on June 21,1983

ABSTRACT: Lesions of the ventromedial-arcuate (VMH-ARC) region of the hypothalamus result in impaired growth accompanied by a marked suppression in spontaneous GH secretory bursts. We studied the effects of an analog of the recently characterized human pancreas GH-releasing factor hpGRF (1-40) on GH secretory dynamics in freelymoving chronically cannulated rats bearing electrolytic lesions of the VMH-ARC. Intravenous administration of the hpGRF analog (hPGRFa) caused a dramatic surge of GH within 5 min; plasma GH levels rose to values as high as $2900 \mathrm{ng} / \mathrm{ml}$ and remained significantly elevated for 15-30 min post treatment. The simultaneous iv administration of somatostatin-14 and hpGRFa resulted in a significant inhibition of the hpGRFa-induced GH release at 5 min but not at $15 \mathrm{~min}$. These results clearly demonstrate that impaired GH secretion resulting from VMH-ARC lesions can be restored by hPGRF. The findings are promising in that hpGRF and its analogs may provide valuable agents for the diagnosis and treatment of disorders of growth secondary to CNS dysfunction.

The most common form of GH deficiency in childhood is thought to be due to hypothalamic dysfunction (1). It is now well recognized that $\mathrm{GH}$ secretion is regulated by at least two hypothalamic neurohormones - a GH releasing factor, GRF, which has not been fully characterized, and a GH-release inhibiting factor, somatostatin (2). The ventromedial-arcuate (VMH-ARC) region of the hypothalamus has been implicated as an important neural locus for GH regulation, since electrical stimulation of this brain region causes a rise in plasma $\mathrm{GH}(3,4)$ whereas lesions result in growth retardation $(5,6)$ accompanied by a marked suppression in spontaneous GH surges $(7,8)$. We have demonstrated that the latter is not due to increased release of somatostatin ( 8 ) and have suggested that the GH suppression is a consequence of damage to putative GRF neurons localized in the VMH-ARC. The recent isolation and characterization of peptides, from human pancreas (hp) tumors $(9,10)$, which exhibit high GH-releasing activity and appear to be identical in biological activity to the still unidentified hypothalamic GRF $(9-12)$ provides a useful tool to evaluate this hypothesis. We report here that an analog of $\operatorname{hPGRF}(1-40),\left[\mathrm{Ala}^{34}, \operatorname{Ser} 38, \operatorname{Arg} 40\right] \operatorname{hpGRF}(1-40)-\mathrm{OH}$, successfully restores high-amplitude GH secretory pulses in GH-deficient rats bearing lesions of VMH-ARC.

\section{MATERIAL AND METHODS}

Adult male Sprague-Dawley rats (320-360 g) were implanted with chronic intracardiac venous cannulae and received bilateral electrolytic lesions of the VMH-ARC by methods previously described (8). Shamoperated control rats were treated identically to lesioned animals but the lesionmaker was not turned on. After surgery the animals were placed directly in isolation test chambers (lights on between 0600$1800 \mathrm{~h}$ ) with Purina rat chow and tap water available ad libitum. Following recovery of preoperative body weight, a 6 -h basal hormonal profile was obtained from both groups of rats. Subsequently, VMH-ARClesioned rats were given 3 iv bolus injections, 90 min apart (at 1030,1200 and $1330 \mathrm{~h}$ ), of the hpGRF analog $\left(h^{\prime} G R F_{a}\right)$. The peptide was synthesized by solid phase techniques with a Beckman 990 peptide synthesizer (13), and was diluted in normal saline just prior to use to attain a concentration of $10 \mu \mathrm{g} / 0.3 \mathrm{ml}$. As a control, VMH-ARC-lesioned rats

1) Correspondence: Department of Endocrinology, Montreal Children's Hospital, 2300 Tupper Street, Montreal, Quebec H3H IP3 received 3 iv injections, at the same time points, of another hypothalamic releasing factor, TRH (Hoechst Canada, Inc.), in a dose of $10 \mu \mathrm{g} / 0.3 \mathrm{ml}$. To study the interaction between somatostatin and hpGRF in vivo, we administered iv $208 \mu \mathrm{g}$ somatostatin-14 (Beckman Instruments, Palo Alto, CA) simultaneously with $10 \mu \mathrm{g}$ hpGRF a to VMH-ARC-lesioned animals at $1030 \mathrm{~h}$ and compared the $\mathrm{GH}$ response to that observed following administration of hpGRFa alone at $1330 \mathrm{~h}$. Blood samples were withdrawn every $15 \mathrm{~min}$ for periods of $6 \mathrm{~h}(1000-1600 \mathrm{~h})$ from all rats. In order to document the rapidity of the response, a blood sample was obtained 5 min after each injection. All blood samples were immediately centrifuged and plasma was separated and stored at $-20 \mathrm{C}$ for subsequent assay of $\mathrm{GH}$, insulin and glucose (8). At the termination of the experiments (6-10 weeks post lesion) the animals were killed by rapid decapitation. The extent and location of the lesions were verified and pituitary $\mathrm{GH}$ concentration was determined as previously described (8). Student's two-tailed and paired $\underline{t}$ tests were used for statistical comparisons.

\section{RESULTS}

The landmarks of the VMH-ARC lesion were similar to those delineated earlier (8). Lesions of the VMHARC $(n=6)$ caused a severe suppression in amplitude and duration of spontaneous GH secretory episodes, with peak GH values rarely exceeding $80 \mathrm{ng} / \mathrm{ml}$ compared to $>500 \mathrm{ng} / \mathrm{ml}$ in sham controls $(n=5)$ (mean 6-h plasma GH levels + SE: $14.2+2.1$ vs $147.5+17.1$ $\mathrm{ng} / \mathrm{ml} ; \underline{\mathrm{P}}<0.001)$. Administration of TRH faiTed to significantly alter the suppressed $G H$ secretory profile of VMH-ARC-lesioned rats (Figs. IA,C). In striking contrast, hpGRF a caused a dramatic surge of $\mathrm{GH}$ within 5 min after injection and plasma $\mathrm{GH}$ rose to levels as high as $2900 \mathrm{ng} / \mathrm{ml}$ (Figs. IB,D). The mean 6-h plasma GH levels of the 2 groups of rats are shown in Figure 2. Compared to TRH-treated controls, plasma $\mathrm{GH}$ levels were significantly elevated at 5, 15 and 30 min after the first hpGRFa bolus and at 5 and $15 \mathrm{~min}$ after the third bolus. However, there was no significant difference in mean plasma GH levels between the two groups after the $1200 \mathrm{~h}$ injection. There was no significant effect of hpGRFa at any time point on either plasma insulin or plasma glucose levels. As shown in Figure 3 , the concomitant administration of somatostatin-14 and hpGRFa at $1030 \mathrm{~h}$ resulted in a significant inhibition of the hPGRFa-induced $\mathrm{GH}$ release at $5 \mathrm{~min}(17.1+10.2$ vs $811.5 \pm 309.6$ $\mathrm{ng} / \mathrm{ml} ; \underline{\mathrm{p}}<0.05)$ but not at $15 \min (525 . \overline{8} \pm 132.9$ 

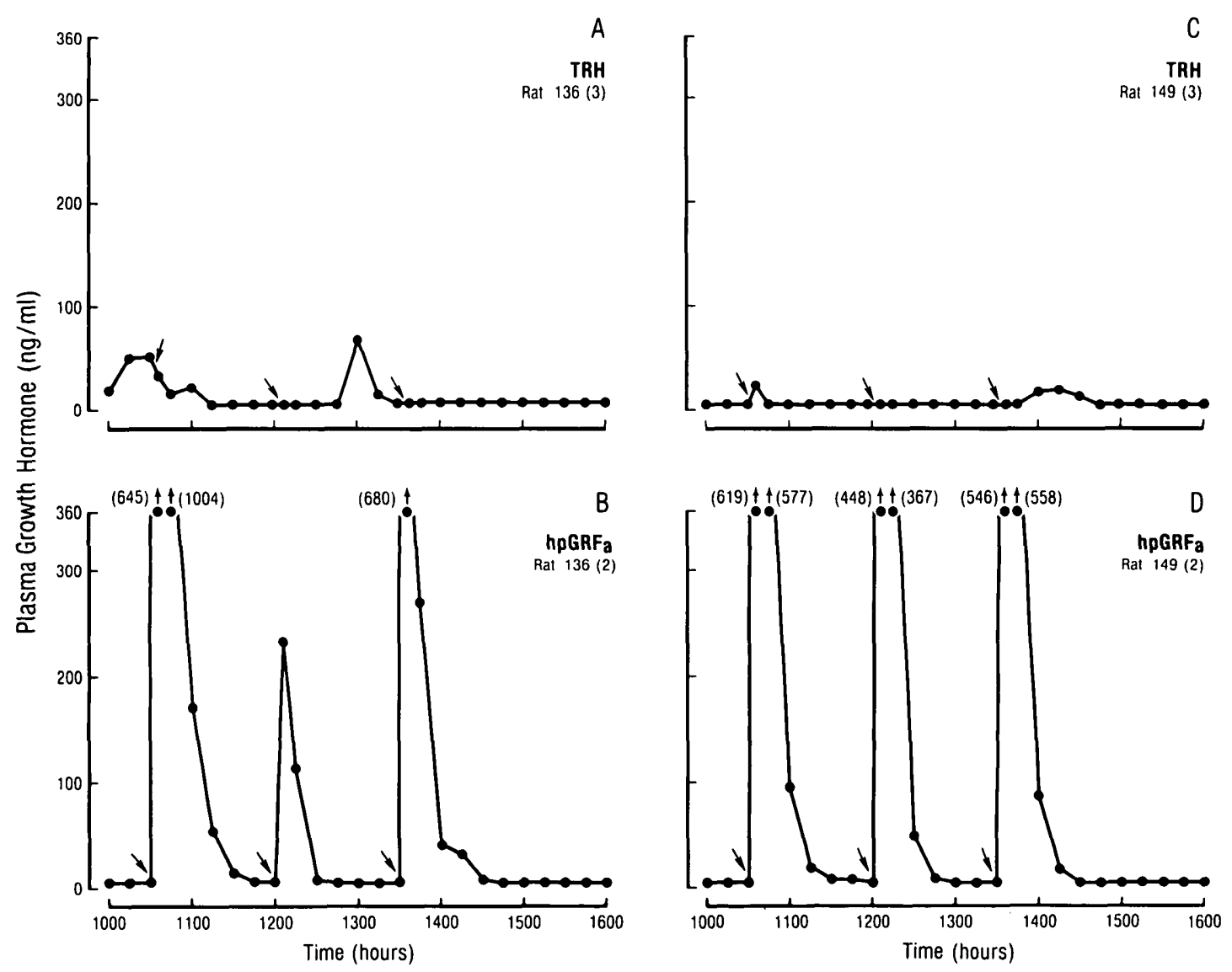

Fig. 1. Effect of iv administration of $10 \mu \mathrm{g}$ of either TRH $(A, C)$ or $h p G R F_{a}(B, D)$ on individual, representative six-hour GH secretory profiles in VMH-ARC-lesioned rats. Arrows indicate time of injection.

vs $500.6 \pm 111.8 \mathrm{ng} / \mathrm{ml}$ ) post injection.

\section{DISCUSSION}

The present findings clearly demonstrate that impaired GH secretion resulting from VMH-ARC lesions can be restored by the administration of an analog of hpGRF. High GH-releasing activity was also observed with a ten-fold lower dose of hpGRFa. These results, together with the recent immunohis tochemical detection of hpGRF-like immunoreactivity in both ARC and VMH nuclei (14), provide strong support for the view that the putative GRF neurons are localized in the VMH-ARC region of the brain.

Possible explanations for the weak response to hpGRFa at $1200 \mathrm{~h}$ may be related to pituitary GH depletion, down-regulation of GRF receptors, interference by endogenous somatostatin, or perhaps some combination of these factors. It is unlikely that it is due entirely to pituitary GH depletion, since the pituitary GH content of these VMH-ARC-lesioned rats $(662 . \pm 119.8 \mu \mathrm{g})$ was sufficient to permit a heal thy response to hpGRF amount of $\mathrm{GH}$ released after the first bolus. It is conceivable that the lack of effect at this time point was due to down-regulation of GRF receptors. In the normal rat, GH is released episodically at 3.3-h intervals, with plasma GH levels undetectable between surges (15); thus, somatotroph GRF receptors may be less sensitive to GRF during the intervening trough periods. Finally, it is also possible that endogenous levels of the inhibitory peptide somatostatin were antagonizing the effects of hpGRFa. It has already been demonstrated in vitro that

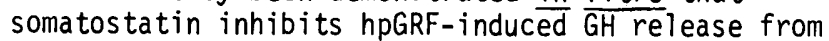
dispersed rat pituitary cells in typical noncompetitive antagonism $(11,12)$. The present finding, in vivo, that somatostatin-14 can inhibit hpGRFainduced GH release was not unexpected; however, the data suggest that the duration of biological activity of hpGRF may be longer than that of somatostatin-14.

The demonstration, in vivo, of potent GH-releasing activity of an analog of $\operatorname{hpGRF}(1-40)$, with substitutions in positions 34,38 and 40 , is consistent with the earlier in vitro reports $(9,10)$ indicating that the full biological activity of hpGRF resides in the $\mathrm{N}$-terminal 28 amino acids. The evidence presented here in animals with hypothalamic damage is promising in that hpGRF and its analogs may provide valuable agents for the diagnosis and treatment of disorders of growth secondary to CNS dysfunction, e.g., idiopathic hypopituitarism.

\section{ACKNOWLEDGEMENTS}

This research was supported by grants from the Medical Research Council of Canada (MT-6837) and the NIH (AM-18811). G.S.T. is a scholar, and R.E a fellow, of the Quebec Medical Research Council. We gratefully acknowledge the interest and assistance of Drs. R. Guillemin and P. Brazeau, and the technical expertise of $W$. Gurd and L. Wanamaker. We thank the NIADDK for generous supplies of rat GH RIA materials. 


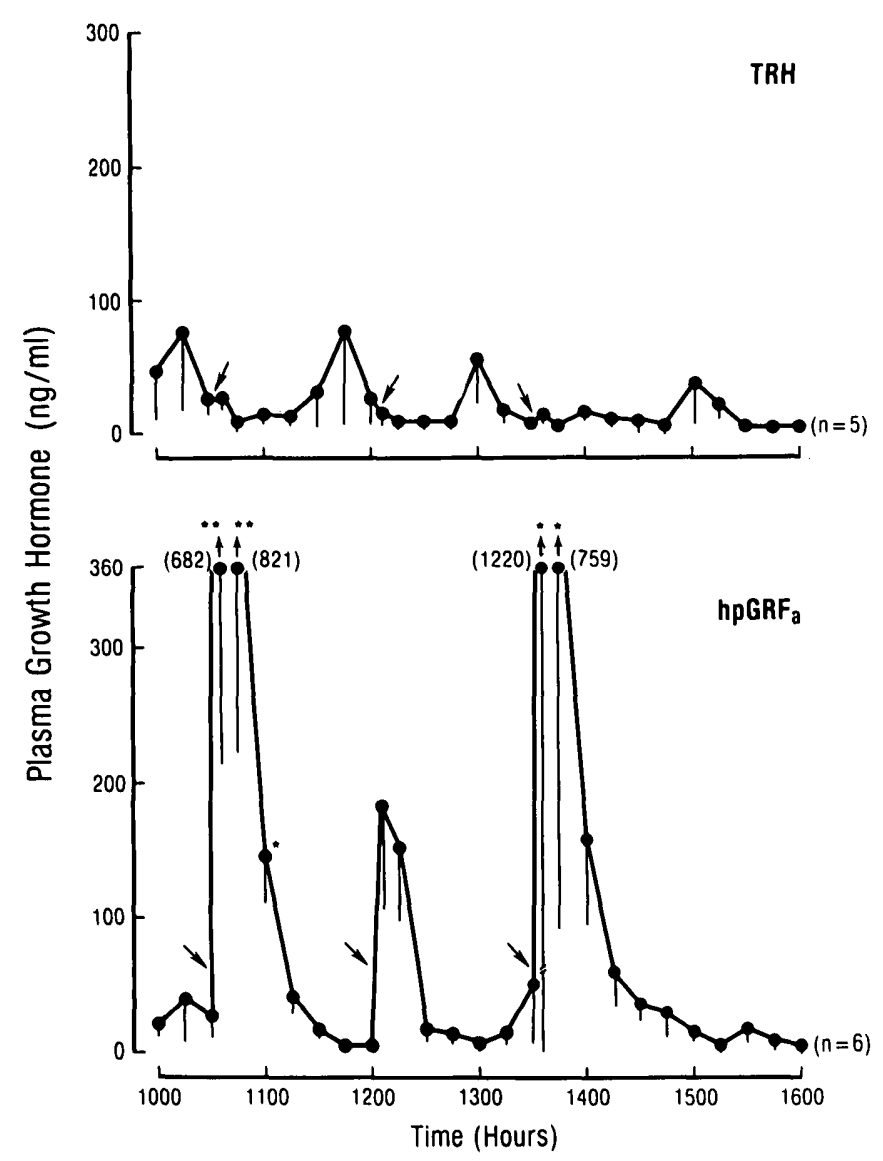

Fig. 2. Mean 6-h plasma GH levels in VMH-ARClesioned rats given 3 iv bolus injections of either TRH or hpGRFa. Arrows indicate time of injection. Vertical lines represent the SEM. The number of animals in each group is shown in parentheses. $\star \underline{p}<0.05, \quad \star \star \underline{p}<0.01$.

\section{REFERENCES}

1. Kaplan SA 1975 Hypopituitarism. In: Gardner LI (ed) Endocrine and Genetic Diseases of Childhood and Adolescence. WB Saunders, Philadelphia, p 106

2. Martin JB, Brazeau P, Tannenbaum GS, Willoughby J0, Epelbaum J, Terry LC, Durand D 1978 Neuroendocrine organization of growth hormone regulation. In: Reichlin S, Baldessarini $R$, Martin JB (eds) The Hypothalamus. Raven Press, New York, p 329

3. Frohman LA, Bernardis LL, Kant KJ 1968 Hypothalamic stimulation of growth hormone secretion. Science 162:580

4. Martin JB 1972 Plasma growth hormone (GH) response to hypothalamic or extrahypothalamic electrical stimulation. Endocrinology 91:107

5. Reichlin S 1960 Growth and the hypothalamus. Endocrinology 67:760

6. Frohman LA, Bernardis LL 1968 Growth hormone and insulin levels in weanling rats with ventromedial hypothalamic lesions. Endocrinology 82:1125

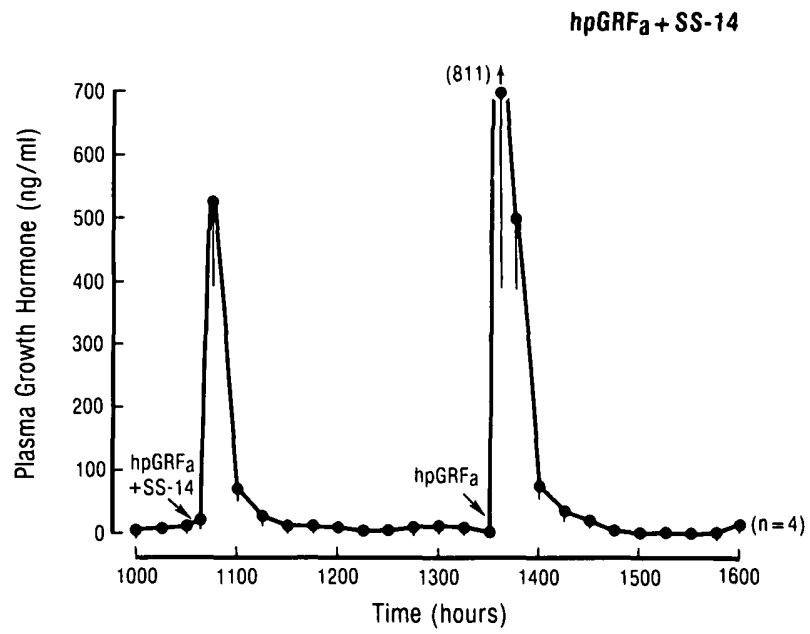

Fig. 3. Effect of the simultaneous iv administration of hpGRFa $(10 \mu \mathrm{g})$ and somatostatin (SS)-14 (208 $\mu \mathrm{g})$ to VMH-ARC-lesioned animals at $1030 \mathrm{~h}$ in comparison to that observed in response to $h G_{R F}$ alone at $1330 \mathrm{~h}$. Vertical lines represent the SEM. The number of animals studied is shown in parentheses.

7. Martin JB, Renaud LP, Brazeau P 1974 Pulsatile growth hormone secretion: suppression by hypothalamic ventromedial lesions and by long-acting somatostatin. Science 186:538

8. Eikelboom R, Tannenbaum GS 1983 Effects of obesity-inducing ventromedial hypothalamic lesions on pulsatile growth hormone and insulin secretion: evidence for the existence of a growth hormone-releasing factor. Endocrinology 112:212

9. Guillemin R, Brazeau P, Bobhlen P, Esch F, Ling N, Wehrenberg WB 1982 Growth hormone-releasing factor from a human pancreatic tumor that caused acromegaly. Science 218:585

10. Rivier J, Spiess J, Thorner M, Vale W 1982 Characterization of a growth hormone-releasing factor from a human pancreatic islet tumour. Nature 300:276

11. Brazeau P, Ling N, Buhlen P, Esch F, Ying SY, Guillemin R 1982 Growth hormone releasing factor, somatocrinin, releases pituitary growth hormone in vitro. Proc Natl Acad Sci USA 79:7909

12. Vale W, Vaughan J, Yamamoto G, Spiess J, Rivier J 1983 Effects of synthetic human pancreatic (tumor) GH releasing factor and somatostatin, triiodothyronine and dexamethasone on $\mathrm{GH}$ secretion in vitro. Endocrinology 112:1553

13. Ling $N$, Esch $F$, Davis D, Mercado M, Regno M, Byhlen P, Brazeau P, Guillemin R 1980 Solid phase synthesis of somatostatin-28. Biochem Biophys Res Commun 95:945

14. Bloch B, Brazeau P, Ling N, Bohlen P, Esch F, Wehrenberg WB, Benoit R, Bloom F, Guillemin R 1983 Immunohistochemical detection of growth hormone-releasing factor in brain. Nature $301: 607$

15. Tannenbaum GS, Martin JB 1976 Evidence for an endogenous ultradian rhythm governing growth hormone secretion in the rat. Endocrinology $98: 562$ 